\title{
Determination of Metastable Zone Width, Induction Period and Interfacial Energy of a Ferroelectric Crystal - Potassium Ferrocyanide Trihydrate (KFCT)
}

\author{
R. KANAGADURAI*, R. DURAIRAJAN ${ }^{\#,}$ R. SANKAR ${ }^{\S}$, \\ G. SIVANESAN, S. P. ELANGOVAN" and R. JAYAVEL ${ }^{\S}$
}

\author{
*Department of Physics, R.S. Govt. College, Thanjavur-613 005, India. \\ \#Department of Chemistry, R.S.Govt. College, Thanjavur-613 005, India. \\ ${ }^{\S}$ Crystal Growth Centre, Anna University, Chennai-600 025, India. \\ J.J.College of Arts and Science, Pudukkottai-622 404, Tamil Nadu, India. \\ srkanagadurai@yahoo.co.in
}

Received 7 July 2009; Accepted 27 August 2009

\begin{abstract}
An order-disorder type potassium ferrocyanide trihydrate (KFCT) is a coordination compound forming lemon- yellow monoclinic ferroelectric crystals with curie temperature $251 \mathrm{~K}$. KFCT crystals have been grown by temperature lowering solution growth technique. Solubility of KFCT has been determined for various temperatures. Metastable zone width, induction period and interfacial energy were determined for the aqueous solution of KFCT. Bulk crystal of potassium ferrocyanide trihydrate was grown with the optimized growth parameters. The grown crystal possesses good optical transmission in the entire UV-Visible region
\end{abstract}

Keywords: Crystal growth, Nucleation, Ferroelectric crystal, KFCT.

\section{Introduction}

Ferroelectric materials possess broad range of unique properties, such as high dielectric permittivity, high piezoelectric constant, electromechanical coupling and high pyroelectric coefficient, etc. They are widely used in industry, military, health care and domestic applications including piezoelectric ignition devices, ultrasonic transducers, micropositioning devices, high dielectric constant capacitors, wide-aperture electrooptic shutters, colour filters and ferroelectric $\mathrm{RAM}^{1-4}$. Ultrahigh piezoelectric effect has made these crystals as leading candidate for application in transducers, sensors and actuators especially in the field of medical ultrasonic imaging and under water communication ${ }^{5,6}$. Intensive studies have been made on these materials due to their promising applications in microelectronic devices as well as in smart-sensing and self-actuating microsystems ${ }^{7,8}$. Kanagadurai et al. ${ }^{9}$ have reported the growth of smaller size single crystals of KFCT by using 
silica gel method. An attempt is made in this work to grow bulk crystals of KFCT with a systematic investigation made on the experimental determination of solubility, metastable zone width and induction period values. The interfacial energy has been evaluated using the experimentally determined induction period values. With the optimized growth parameters excellent bulk crystals of KFCT of maximum size $18 \times 18 \times 5 \mathrm{~mm}^{3}$ have been grown by temperature lowering solution growth technique.

\section{Experimental}

The solubility corresponds to saturation i.e. to equilibrium between a solid and its solution at a given temperature and pressure. Thermodynamically, this means that the chemical potential of the pure solid is equal to the chemical potential of the same solute in the saturated solution. The growth rate of a crystal depends on its solubility and temperature. Solubility data of a material governs the amount of material, which is available for the growth and hence defines the total size of the crystal. Solvent and solubility factors define the supersaturation which is the driving force for the rate of crystal growth. Hence for a material to grow as a crystal, determination of its solubility in a particular solvent is an important and essential criterion.

The growth of a crystal by conventional slow cooling technique requires accurate solubility temperature data. The solubility of KFCT (analar grade) was determined in the temperature range $30-45{ }^{\circ} \mathrm{C}$. The solubility was determined by dissolving the calculated amounts of the KFCT in deionized water. This solution was heated and kept for slow evaporation to dryness at room temperature. The purity of the salt was improved by successive recrystallization. After attaining saturation, the equilibrium concentration of the solute was estimated gravimetrically. The same procedure was repeated to estimate the equilibrium concentration at various temperatures. The solubility of potassium ferrocyanide trihydrate in water is plotted in Figure 1.

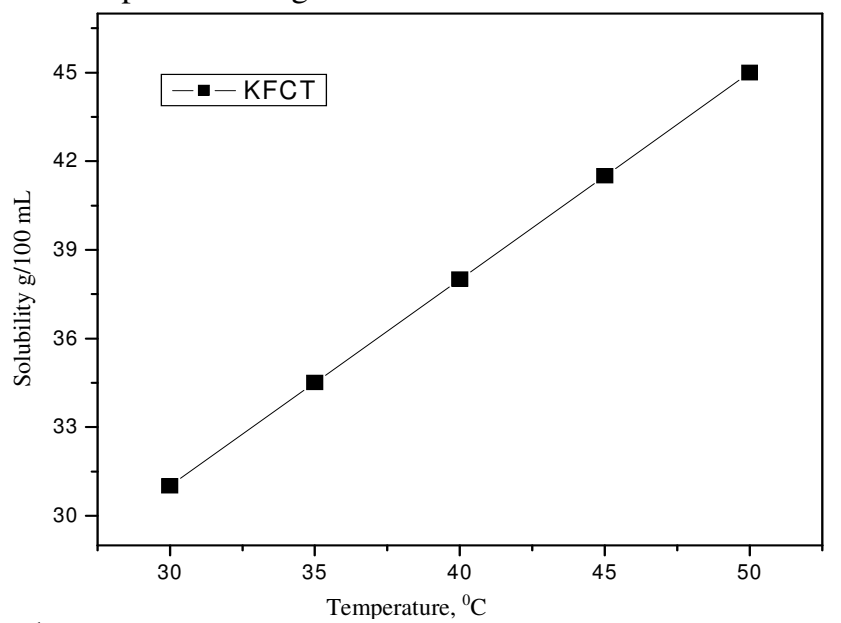

Figure 1. Solubility of KFCT as a function of temperature in aqueous solution.

\section{Metastable zone width and induction period measurements}

The saturated solution of purified KFCT was prepared in accordance with the presently determined data for the nucleation experiments. The studies were carried out in a constant temperature bath, controlled to an accuracy of $\pm 0.05^{\circ} \mathrm{C}$, provided with a cryostat for cooling below room temperature. A constant volume of $150 \mathrm{~mL}$ of the solution was used throughout the experiment. The saturated solution was heated $5{ }^{\circ} \mathrm{C}$ above the saturation temperature for 
homogenization and was kept at the superheated temperature for one hour before subjecting it to slow cooling. It was continuously stirred using a motorized stirrer to ensure homogeneous concentration and temperature in the entire volume of the solution. The metastable zone width was measured by the conventional method ${ }^{10,11}$ in which the equilibrium-saturated solution is cooled from the superheated temperature until the first visible crystal is observed. The temperature of the bath was reduced at a rate of $0.5^{\circ} \mathrm{C}$ per minute with continuous stirring after the stabilization. The temperature at which the first speck of a particle appeared was noted. The first speck of crystal obtained is considered as critical nucleus. The induction period, the time taken for the formation of the critical nucleus, of pure KFCT solution was measured by isothermal method ${ }^{11}$. The experiment was repeated, to ensure reproducibility, for solutions saturated at temperatures $30,35,40$ and $45^{\circ} \mathrm{C}$. The actual solubility, induction period and metastable zone widths are shown in Table 1.

Table 1. Solubility, induction period and metastable zone width of KFCT.

\begin{tabular}{ccccc}
\hline $\begin{array}{c}\text { Saturation } \\
\text { temperature, }{ }^{\circ} \mathrm{C}\end{array}$ & $\begin{array}{c}\text { Solubility, } \\
\mathrm{g} / 100 \mathrm{~mL}\end{array}$ & $\begin{array}{c}\text { Nucleation } \\
\text { temperature, }{ }^{\circ} \mathrm{C}\end{array}$ & Induction period $(\mathrm{T}), \mathrm{s}$ & $\begin{array}{c}\text { Metastable } \\
\text { zone width, }{ }^{\circ} \mathrm{C}\end{array}$ \\
\hline 30 & 31.0 & 18.5 & 360 & 11.5 \\
35 & 34.5 & 31.1 & 128 & 3.9 \\
40 & 38.0 & 37.3 & 80 & 2.7 \\
45 & 41.5 & 41.9 & 25 & 3.1 \\
\hline
\end{tabular}

Interfacial tension

The interfacial tension $(\sigma)$ of the crystal and solution is an important parameter involved in the theory of nucleation and growth kinetics. The interfacial tension has been calculated on the basis of the classical theory of homogeneous nucleation ${ }^{12-14}$. In order to estimate the critical nucleation parameters of KFCT, the interfacial tension has been calculated using the experimentally measured induction period values by the relation

$$
\ln \tau=-\ln \mathrm{B}+\frac{16 \pi \sigma^{3} V^{2} N}{3 R^{3} T^{3}(\ln S)^{2}}
$$

Where $\sigma$ is the interfacial tension, $\mathrm{V}$ is the molar volume of the crystal, $\mathrm{N}$ is the Avogadro number, $R$ is the gas constant and $S$ is the relative supersaturation $\left(S=C / C^{*}\right)$ where $C$ is the actual concentration and $C^{*}$ is the equilibrium concentration. The function $\ln$ $\mathrm{B}$ weakly depends on temperature and hence there is a linear dependence between $\ln \tau$ and $(\operatorname{lnS})^{2}$ at constant temperature. The interfacial tension of the solid relative to this solution has been calculated from the relation

$$
\sigma^{3}=\frac{3 \ln \tau R^{3} T^{3}(\ln S)^{2}}{16 \pi V^{2} N}
$$

Free energy required to form a spherical nucleus is given by

$$
\Delta G=\frac{4}{3} \pi r^{3} \Delta G_{v}+4 \pi r^{2} \sigma
$$

Where, $\Delta \mathrm{Gv}$ is the energy change per unit volume, $\mathrm{r}$ is the radius of the nucleus at the critical state, the free energy of formation obeys the condition that $\mathrm{d}(\Delta \mathrm{G}) / \mathrm{dr}=0$. Hence the radius of the critical nucleus is expressed as $r^{*}=\frac{-2 \sigma}{\Delta G_{v}}$, where, $\Delta G_{v}=-k T \ln S / v$, where $\mathrm{v}$ is the molar volume, $\mathrm{S}=\mathrm{C} / \mathrm{C}^{*}, \mathrm{C}$-actual concentration and $\mathrm{C}^{*}$-equilibrium concentration. Hence,

$$
r^{*}=-\frac{2 v \sigma}{k T \ln S}
$$


The critical free energy is given by

\section{Bulk crystal growth}

$$
\Delta G^{*}=\frac{16 \pi \sigma^{3} v^{2}}{3 \Delta G_{v}^{2}}
$$

To grow bulk crystal, the supersaturated solution of KFCT was kept in a constant temperature bath with an accuracy of $\pm 0.05{ }^{\circ} \mathrm{C}$ at $45^{\circ} \mathrm{C}$. The seed crystal of KFCT, obtained by slow evaporation method, was suspended in the solution. The temperature of the bath was reduced at the rate of $0.05^{\circ} \mathrm{C}$ per day. Highly transparent single crystal of KFCT was obtained in the time span of 25 days. Crystal of dimensions $18 \times 18 \times 5 \mathrm{~mm}^{3}$ grown from aqueous solution by temperature-lowering method is shown in the Figure 2.
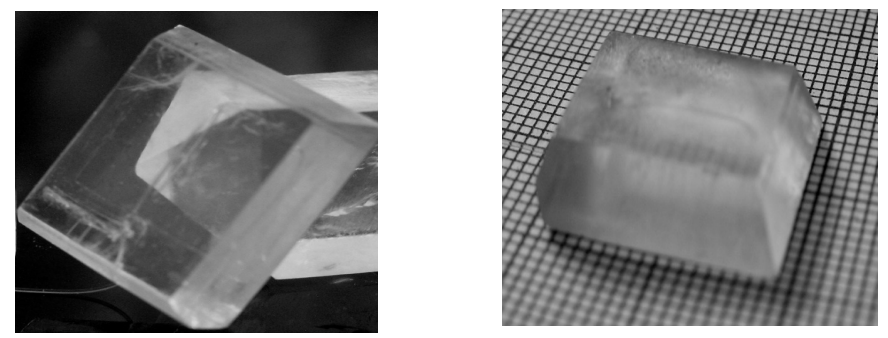

Figure 2. Single crystal of KFCT

\section{Results and Discussion}

The metastable zone width of KFCT as a function of temperature is shown in Figure 3. The numerical values of interfacial energy, critical free energy and radius of the critical nucleus are shown in Table 2. The measured interfacial tension of KFCT varies from 4.484 to 8.500 $\mathrm{mJ} / \mathrm{m}^{2}$. The energy of formation $\left(\Delta \mathrm{G}^{*}\right)$ and radius $\left(\mathrm{r}^{*}\right)$ of the critical nucleus of KFCT were found to be 1.2403 to $0.6786 \mathrm{~kJ} / \mathrm{mol}$ and $8.1954 \mathrm{~nm}$ to $4.4440 \mathrm{~nm}$ respectively at different supersaturation level. Figures $4 \& 5$ show the induction period and interfacial tension as a function of supersaturation for KFCT system respectively. It was observed that the growth rate of a crystal mainly depends on a set of crystal growth parameters like temperature, the degree of supersaturation of the solution, concentration of the solution, etc.

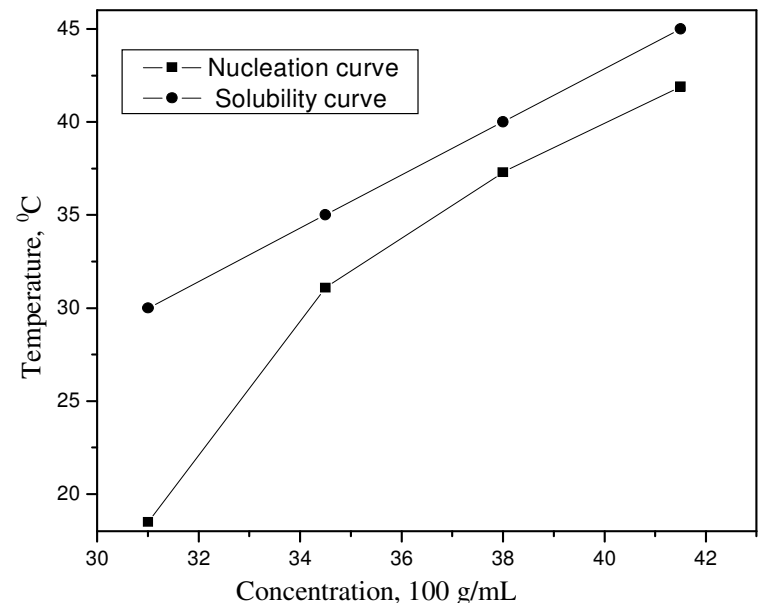

Figure 3. Metastable zone width as a function of temperature. 


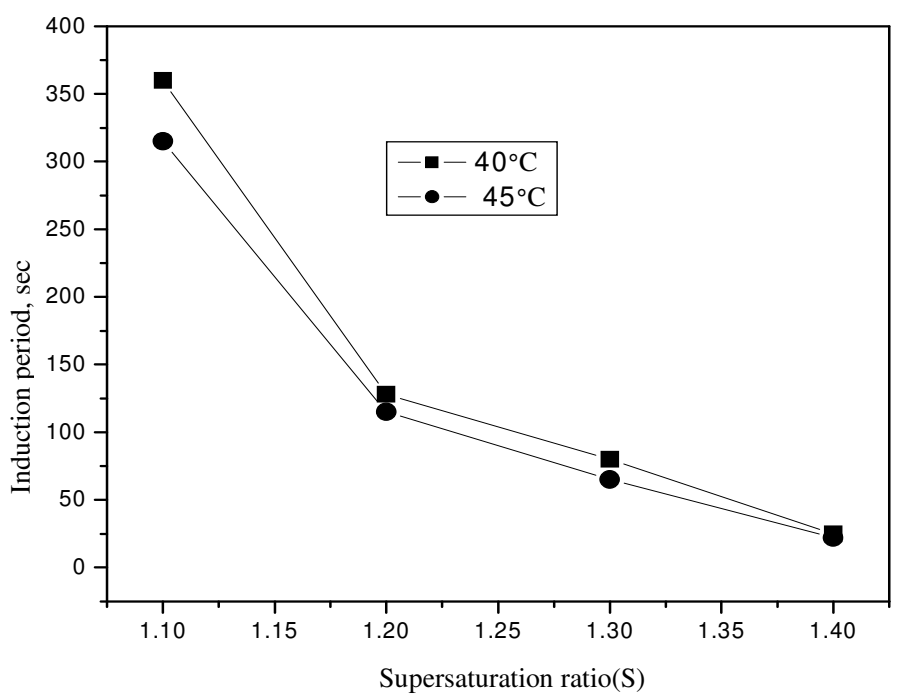

Figure 4. Induction period vs. supersaturation ratio for KFCT solution.

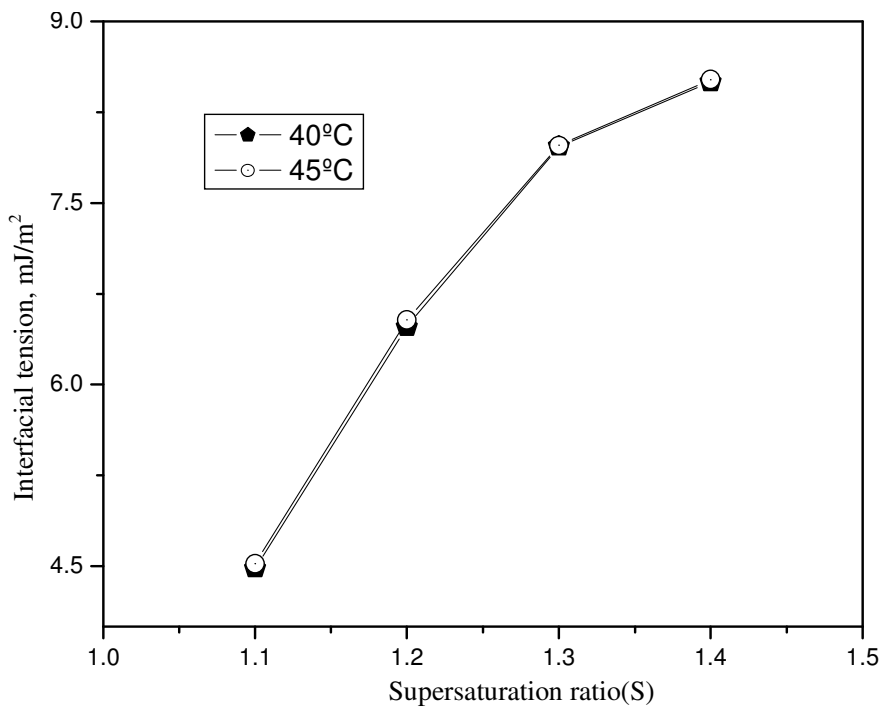

Figure 5. Linear relationship between interfacial tension and supersaturation.

Table 2. Nucleation parameters of the KFCT.

\begin{tabular}{ccccc}
\hline $\begin{array}{c}\text { Saturation } \\
\text { temperature } \\
{ }^{\circ} \mathrm{C}\end{array}$ & $\begin{array}{c}\text { Supersaturat } \\
\text { ion ratio } \\
(\mathrm{S})=\mathrm{C} / \mathrm{C}^{*}\end{array}$ & $\begin{array}{c}\text { Interfacial } \\
\text { tension }(\sigma) \\
\mathrm{mJ} / \mathrm{m}^{2}\end{array}$ & $\begin{array}{c}\text { Critical free energy } \\
\text { of formation }\left(\Delta \mathrm{G}^{*}\right) \\
\mathrm{kJ} / \mathrm{mol}\end{array}$ & $\begin{array}{c}\text { Critical } \\
\text { nucleus }\left(\mathrm{r}^{*}\right), \\
\mathrm{nm}\end{array}$ \\
\hline 30 & 1.1 & 4.484 & 1.2403 & 8.1954 \\
35 & 1.2 & 6.478 & 1.0220 & 6.1909 \\
40 & 1.3 & 7.969 & 0.9184 & 5.3370 \\
45 & 1.4 & 8.500 & 0.6786 & 4.4440 \\
\hline
\end{tabular}




\section{Conclusion}

Nucleation kinetics of potassium ferrocyanide trihydrate has been studied. Growth parameters such as the solubility, metastable zone width, induction period have been determined experimentally. The induction periods of KFCT are found to decreases with increase of supersaturation ratio. The radius of the critical nucleus decreases with increase of supersaturation. The metastable zone widths are also found to decrease with increase of temperatures. It is clear that the free energy change decreases exponentially with increase in super cooling. Also with the increase in interfacial tension, the critical free energy change increases. From the analysis it is worth to note that for particular super cooling, the minimum nucleation barrier exists for KFCT at the interfacial tension $4.484 \mathrm{~mJ} / \mathrm{m}^{2}$. Hence it is concluded that the interfacial tension plays the vital role in nucleation mechanism. Bulk crystals of KFCT have been grown from the optimized growth parameters.

\section{Acknowledgement}

One of the authors (RK) acknowledges the University Grants Commission (UGC), Government of India for providing Teacher Fellowship under the Faculty Development programme (FDP).

\section{References}

1 Scott J F, Ferroelectr Rev., 1998, 1(1), 1.

2 Setter N and Waser R, Acta Mater. 2000, 48, 151.

3 Lysne P C and Percival C M, Ferroelectrics 1976, 10, 129.

$4 \quad$ Newnham R E and Ruschau G R, J Am Ceram Soc., 1991, 74, 463.

5 Scharfschwerdt R, Schirmer O F, Hesse H and Rytz D, Appl Phys, B-LASERS O, 1999, 68(5), 807.

6 Mathey P, Dazzi A, Jullien P, Rytz D and Moretti P, Opt Mater., 2001, 18, 69.

7 Saitoh S, Takeuchi T, Kobayashi T, Harada K, Shimanuki S and Yamashita Y, IEEE

Trans, Ultrason Ferroelectr Freq Control, 1999, 46, 276.

8 Yin J, Jiang B and Cao W, IEEE Trans Ultrason Ferroelectr Freq Control, 2000, 47, 285

9 Kanagadurai R, Sankar R, Sivanesan G, Srinivasan S and Jayavel R, Cryst Res Technol., 2006, 41(9), 853.

10 Nyvlt I, Rychly R and Wutzelova J G, J Cryst Growth, 1970, 6, 151.

11 Zaitseva N P, RashKovich L N and Bagatyarek S V, J Cryst Growth, 1995, 148, 271.

12 Nielson A E and Aig S, J Cryst Growth, 1971, 8, 1.

13 Volmer M and Weber A, J Phys Chem., 1926, 119, 277.

14 Ushasree P M, Muralidharan R, Jayavel R and Ramasamy P, J Cryst Growth, 2000, 210, 741 . 


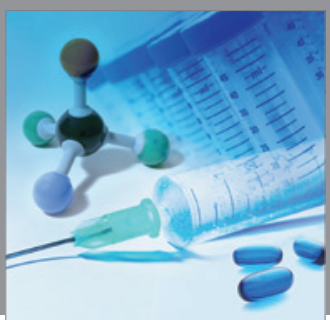

International Journal of

Medicinal Chemistry

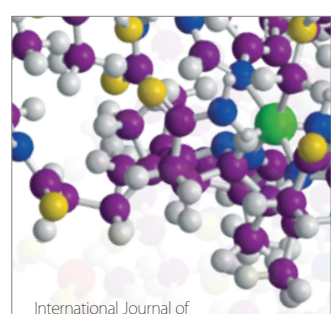

Carbohydrate Chemistry

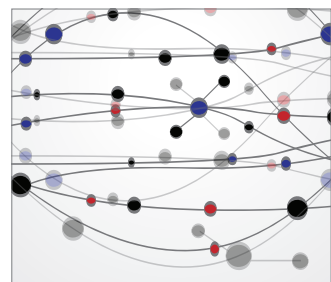

The Scientific World Journal
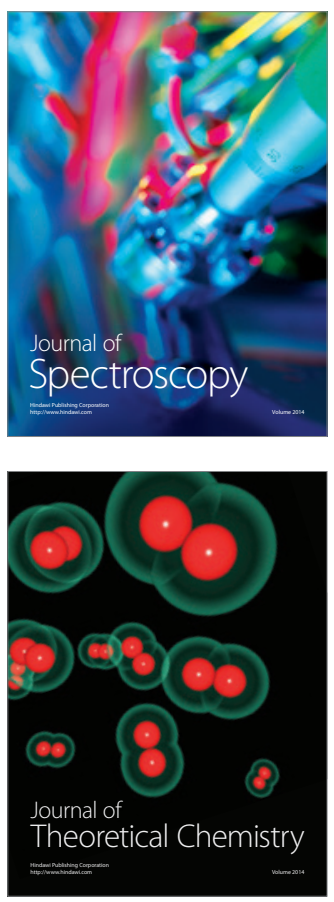
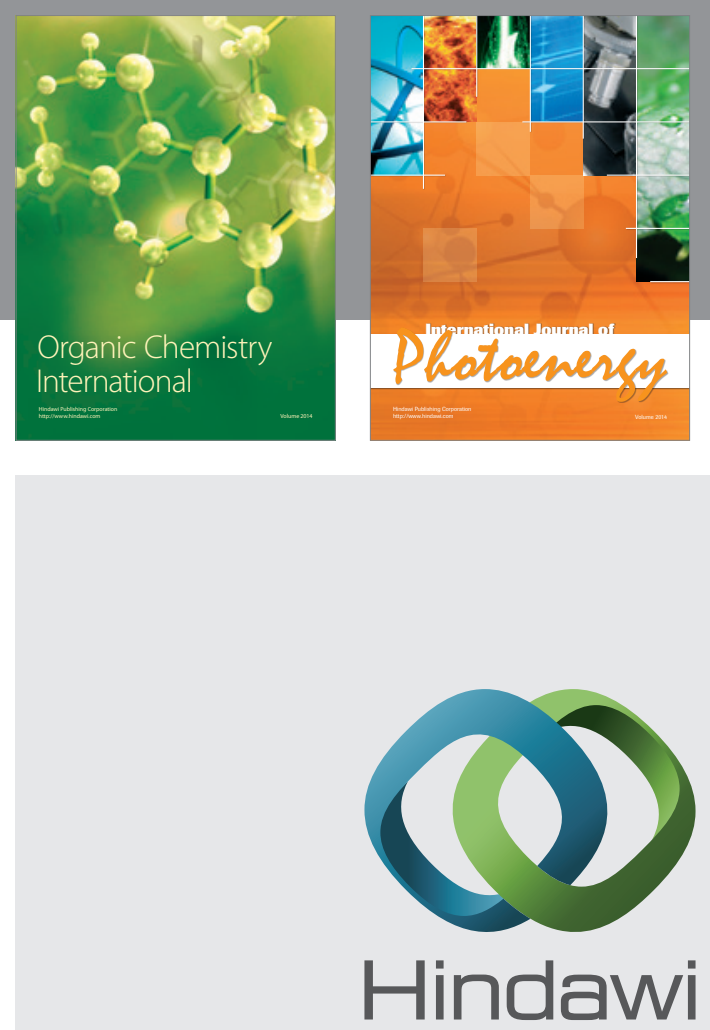

Submit your manuscripts at

http://www.hindawi.com
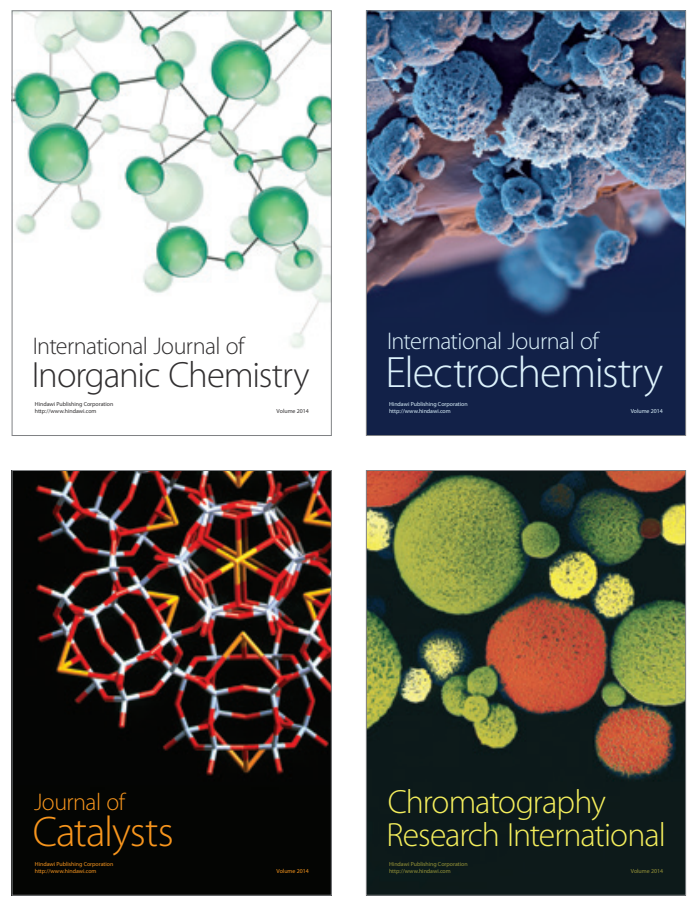
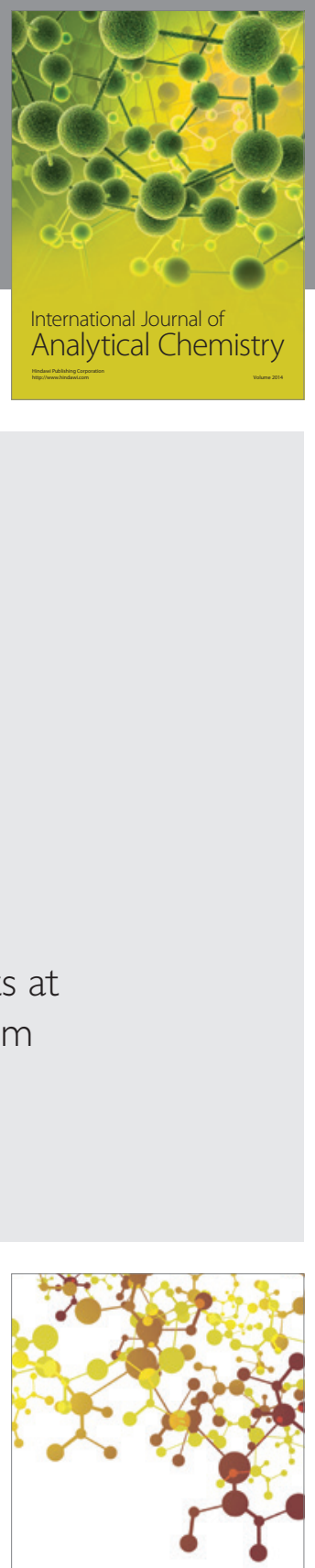

Journal of

Applied Chemistry
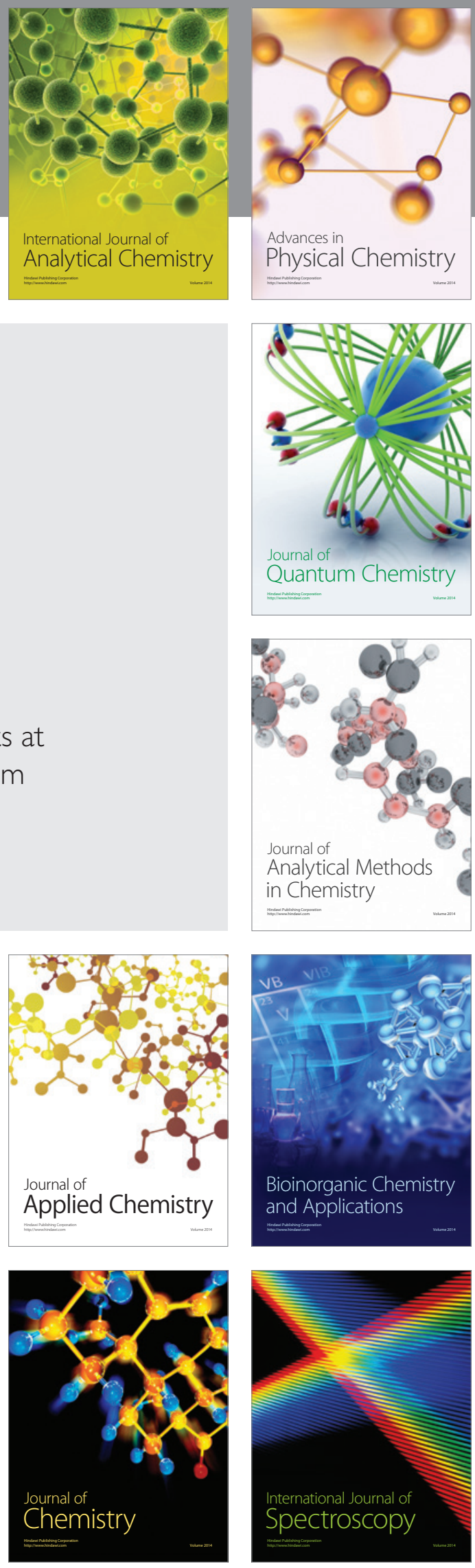